\title{
Efficient Removal of Hexavalent Chromium from Wastewater with Electro-Reduction
}

\author{
Hao Peng ${ }^{1, * \mathbb{D}}$, Yumeng Leng ${ }^{1}$, Qinzhe Cheng ${ }^{1}$, Qian Shang ${ }^{1}$, Jiancheng Shu ${ }^{2, *}$ and Jing Guo ${ }^{1}$ \\ 1 College of Chemistry and Chemical Engineering, Yangtze Normal University, Chongqing 408102, China; \\ yznulym@126.com (Y.L.); yznucqz@126.com (Q.C.); yznusq@126.com (Q.S.); cquguojing@126.com (J.G.) \\ 2 Key Laboratory of Solid Waste Treatment and Resource Recycle, Ministry of Education, Southwest \\ University of Science and Technology, Mianyang 621010, China \\ * Correspondence: cqupenghao@126.com (H.P.); shujc@swust.edu.cn (J.S.); Tel.: +86-151-2303-1643 (H.P.)
}

Received: 19 December 2018; Accepted: 9 January 2019; Published: 15 January 2019

\begin{abstract}
Removal of hexavalent chromium had attracted much attention as it is a hazardous contaminant. An electrocoagulation-like technology electro-reduction was applied. The chromium (VI) in the wastewater was reduced to chromium (III) by the electron supplied by electricity power and $\mathrm{Fe}^{2+}$, formed from corrosion of steel electrodes in acidic conditions. The mechanism and parameters affecting the reaction were investigated. The results optimized by response surface methodology indicated that the influence of single factor on the reduction efficiency followed the order: A: dosage of $\mathrm{H}_{2} \mathrm{SO}_{4}>\mathrm{C}$ : reaction time $>\mathrm{D}$ : reaction temperature $>\mathrm{B}$ : current intensity. The reduction efficiency was hardly affected by current intensity, while it was increased with the increasing of reaction time and acid concentration. The reducing agent, $\mathrm{Fe}^{2+}$ an and extra free electron, acted as a reducing agent and could easily reduce hexavalent chromium to trivalent chromium at high temperatures in an acidic medium.
\end{abstract}

Keywords: electro-reduction; chromium; acidic medium

\section{Introduction}

Chromium is an important strategic metal widely used in many fields due to its excellent properties [1-5]. In the earth, chromium mainly exists in the oxidative states of hexavalent chromium and trivalent chromium. The chromium (III) compounds are relatively stable and have low solubility and mobility. Chromium (VI) mainly exists as chromate $\left(\mathrm{CrO}_{4}{ }^{2-}, \mathrm{HCrO}_{4}{ }^{-}\right)$and dichromate $\left(\mathrm{Cr}_{2} \mathrm{O}_{7}{ }^{2-}\right)$, which has high solubility. The removal of chromium (VI) has attracted much more attention, as it is a hazardous contaminant $[6,7]$.

Currently, many remediation techniques have been developed to remove heavy metal ions from waste water. It can be divided into three species. The traditional one is physical methods, like adsorption [8-11], ion exchange [12], and membrane filtration [7], which are mainly conducted by their physical properties. Due to the different chemical properties of chromium (VI) and chromium (III), chemical precipitation [13], coagulation [14], and chemical reduction [15,16] are often used to remove chromium (VI). Additionally, some biological treatments [17,18] (phytoremediation [19]) are also applied to remove chromium (VI) in waste water and groundwater. Lead sulfate as a precipitation is used to precipitate chromium (VI) and it can remove chromium (VI) from $0.2 \mathrm{~mol} / \mathrm{L}$ to $0.15 \mathrm{mmol} / \mathrm{L}$, as shown in a recent study [13], but lead sulfate is a second pollutant, which is harmful for the environment. At the same time, difficulties and challenges like high costs, large scale application, and causing secondary pollution still remain in current technologies. It is needed to overcome these challenges and develop new, effective techniques for removal of chromium (VI). 
Electricity acting as a clean source is widely used in hydrometallurgy, like electro-oxidation technology [20-22], and treatment of different wastewater, like electrocoagulation [23-25]. Electrocoagulation involves the generation of coagulants by dissolving metal electrodes or free electrons. The metal ions formed are metal hydroxides, like $\mathrm{Al}(\mathrm{OH})^{2+}, \mathrm{Al}(\mathrm{OH})_{2}{ }^{+}$, and $\mathrm{Al}(\mathrm{OH})_{4}{ }^{-}$ for $\mathrm{Al}$ electrode, and $\mathrm{Fe}(\mathrm{OH})^{2+}$ and $\mathrm{Fe}(\mathrm{OH})_{3}$ for Fe electrode. These metal hydroxides have large surface areas and can adsorb soluble organic compounds. In this paper, an electrocoagulation-like technology electro-reduction is applied to reduce $\mathrm{Cr}$ (VI) to $\mathrm{Cr}$ (III). The mechanisms and parameters affecting the reaction are investigated, including dosage of $\mathrm{H}_{2} \mathrm{SO}_{4}$, reaction time, reaction temperature, and current intensity. Response surface methodology [26-28] is also used to predict the optimal reaction conditions and observe the interactions between parameters.

\section{Materials and Methods}

\subsection{Materials}

All chemicals were of analytical grade, including potassium dichromate $\left(\mathrm{K}_{2} \mathrm{Cr}_{2} \mathrm{O}_{7}\right)$ and sulfuric acid $\left(\mathrm{H}_{2} \mathrm{SO}_{4}\right)$, which were collected from Kelong Co., Ltd, Chengdu, China, and used as received without purification.

\subsection{Experimental Procedure}

Reduction experiments were carried out in a batch mode to evaluate the reduction efficiency of electricity for chromium (VI) ions from aqueous solutions. In the batch experiments, a stock solution of $1.000 \mathrm{~g} / \mathrm{L}$ chromium (VI) was prepared by dissolving a certain $\mathrm{K}_{2} \mathrm{Cr}_{2} \mathrm{O}_{7}$ in distilled water. The acidic medium was prepared by adding different volumes of $\mathrm{H}_{2} \mathrm{SO}_{4}$, the current was from a set of electric supply, the anode and cathode used in the experiments were steel slice $(2 \times 2 \mathrm{~cm})$, and the distance of the two electrodes was $2 \mathrm{~cm}$. Further, in each set of experiments, $100 \mathrm{~mL}$ of chromium (VI) was added into a beaker and agitated in a thermostat water-bath shaker at $500 \mathrm{rpm}$. During the experiments, the samples were collected at different intervals ( $5 \mathrm{~min})$, and analyzed for residual concentration of chromium (VI) in the solution [13].

The concentration of chromium (VI) was determined by inductive couple plasma-optical emission spectrometry (ICP-OES). The reduction efficiency $(\eta)$ was calculated as Equation (1):

$$
\eta=\frac{C_{1} \cdot V_{1}-C_{2} \cdot V_{2}}{C_{1} \cdot V_{1}}
$$

where $C_{1}$ and $C_{2}$ are the concentration of chromium in the solution before and after the experiment, $\mathrm{g} / \mathrm{L}$. $\mathrm{V}_{1}$ and $\mathrm{V}_{2}$ is the volume before and after the experiment, $\mathrm{L}$.

\subsection{Experimental Design and Optimization Method}

The adoption of response surface methodology (RSM) to optimize a known process is easy, practical, and economical. Successful RSM optimizations usually consist of three steps. The first step was to design appropriate experiments to efficiently assess the model parameters. The second step was to develop a polynomial model that can be applied to the experimental data through regression, and to verify the model's suitability by applying a statistical test (e.g., lack-of-fit or F-test) [29-31]. The final step was to determine the values of factors that result in the best conditions. A first or second-order polynomial was usually used for RSM analysis, and a second order polynomial was preferred for responses that included a curvature. The general form of such a polynomial is as follows:

$$
y=a_{0}+\sum_{i=1}^{k} a_{i} x_{i}+\sum_{i=1}^{k} a_{i i} x_{i}^{2}+\sum_{i=1}^{k} \sum_{j=1}^{k} a_{i j} x_{i} x_{j}^{2}+\varepsilon(i<j)
$$


where $y$ is the predicted response, $a_{0}$ is a constant, $a_{i}$ is the $i$ th linear coefficient, $a_{i i}$ is the $i$ th quadratic coefficient, $a_{i j}$ is the $i$ th interaction coefficient, $x_{i}$ is an independent variable, $k$ is the number of factors, and $\varepsilon$ is the associated error.

The coefficients of the model were predicted using regression. Details of the parameter estimations for such a model have been reported previously [29-31]. Central composite design (CCD), which was utilized in this study, was the most popular second-order experimental design, and was an efficient approach to providing sufficient information to test the fitness of a model. The CCD approach did not require numerous design points; therefore, it saved the expense and time associated with completing experiments. Many experiments in which CCD had been applied had included three sets: (1) factional factorial runs $\left(2^{\mathrm{k}-1}\right)$, which studied factors at -1 (minimum) and +1 (maximum) levels; (2) center-point runs, which examined factors at a center point of a design space and aided in the understanding of curvature and data replication to evaluate pure errors; and (3) axial or star-point runs (2k), which set all factors to 0 (i.e., the center point), except for one factor with values of $+\alpha$ and $-\alpha$ [29-31].

In this study, the Design-Expert software (Version 8.0.6) was used to design the experiments. CCD was applied to investigate the impact of process parameters on the leaching efficiency of vanadium from vanadium-chromium residue. The experiment results were incorporated to determine an empirical equation that could predict the optimal operating conditions. The operation factors included the mass ratio of $\mathrm{NaOH}$ to vanadium-chromium residue, volume ratio of $\mathrm{H}_{2} \mathrm{O}_{2}$ to mass of vanadium-chromium residue, reaction time, reaction temperature, stirring rate, and liquid-to-solid ratio. The satisfaction degree of the polynomial equation developed through a regression of Equation (2) was assessed on the basis of $R^{2}$ and $R_{A d j}{ }^{2}$. $R^{2}$ was a measurement of the amount of variation around the mean; it was determined for a model using Equation (3). $R_{A d j}{ }^{2}$ was a measurement of the amount of variation around the mean; it was determined by experiments and was regulated for the number of terms in the model using Equation (4).

$$
\mathrm{R}_{\mathrm{adj}}{ }^{2}=1-\frac{\mathrm{R}^{2}=1-\frac{\mathrm{S}_{\text {residual }}}{\mathrm{S}_{\text {model }}-\mathrm{S}_{\text {residual }}}}{\left(\mathrm{S}_{\text {model }}+\mathrm{S}_{\text {residual }}\right) /\left(\mathrm{Z}_{\text {model }}+\mathrm{Z}_{\text {residual }}\right)}
$$

where $S$ is the sum of squares and $Z$ is the degrees of freedom. The statistical importance of the model was verified with adequate precision using Equations (5) and (6). These equations were used to determine the signal-to-noise ratio.

$$
\begin{gathered}
\text { Adequate precision }=\frac{\max \hat{y}-\min \hat{y}}{\sqrt{\bar{V}(\hat{y})}} \\
\bar{V}(\hat{y})=\frac{1}{n} \sum_{i=1}^{n} V(\hat{y})=\frac{p \sigma^{2}}{n}
\end{gathered}
$$

where $\hat{y}$ is the predicted response, $p$ is the number of model parameters, $\sigma^{2}$ is the residual mean square, and $\mathrm{n}$ is the number of experiments.

\section{Results and Discussion}

\subsection{Reduction of Chromium (VI)}

\subsubsection{Reaction mechanism}

The electro-reduction process, similar to electrocoagulation, which is expressed in Figure 1, involved the following stages of reducing agent formation and subsequent reduction of chromium (VI) and chromium (III). 


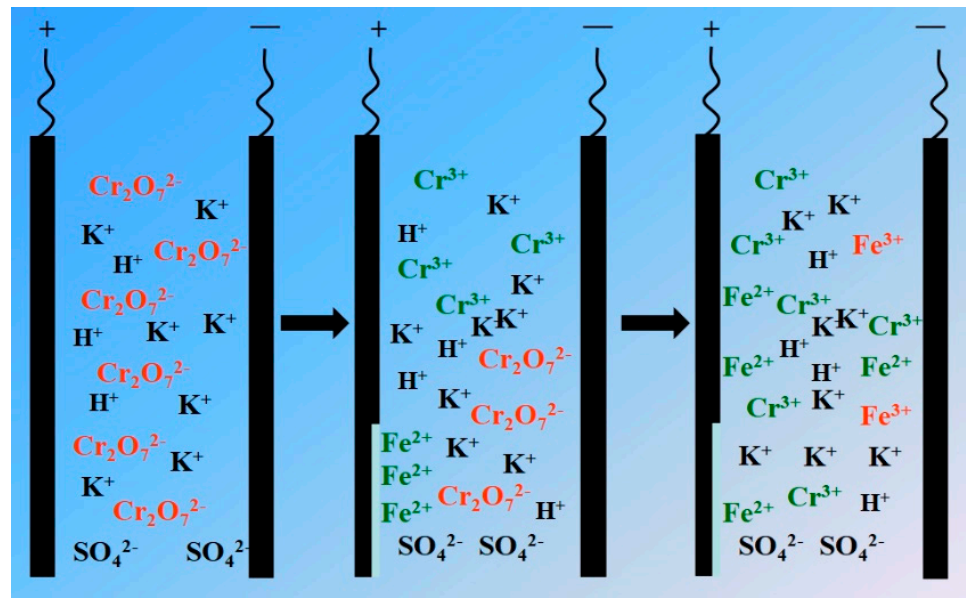

Figure 1. The reaction model for the electro-reduction process.

The first step was the formation of reducing agent. During the reduction process, a potential was applied. The anode steel slice was almost made up of iron and it was oxidized by electricity and formed $\mathrm{Fe}^{2+}$. The mechanism was described in Equation (7), as follows:

Anode:

$$
\begin{gathered}
\mathrm{Fe}^{0}(\mathrm{~s}) \rightarrow \mathrm{Fe}^{2+}(\mathrm{aq})+2 \mathrm{e}^{-} \\
2 \mathrm{H}_{2} \mathrm{O}(\mathrm{l}) \rightarrow 4 \mathrm{H}^{+}(\mathrm{aq})+\mathrm{O}_{2}(\mathrm{~g})+4 \mathrm{e}^{-}
\end{gathered}
$$

Cathode:

$$
2 \mathrm{H}^{+}(\mathrm{aq})+2 \mathrm{e}^{-} \rightarrow \mathrm{H}_{2}(\mathrm{~g})
$$

Overall:

$$
\mathrm{Fe}^{0}+2 \mathrm{H}_{2} \mathrm{O} \rightarrow \mathrm{Fe}^{2+}++2 \mathrm{H}_{2}+\mathrm{O}_{2}+2 \mathrm{e}^{-}
$$

The second step was the reduction reaction between reducing agent and oxidant. In this process, it was the reaction between $\mathrm{Fe}^{2+}$ and chromium (VI). The reactions were described in Equations (11) to (15) by taking the $\mathrm{pH}$ of wastewater into account.

$0.5<\mathrm{pH}<6.5$ :

$$
6 \mathrm{Fe}^{2+}(\mathrm{aq})+\mathrm{Cr}_{2} \mathrm{O}_{7}^{2-}(\mathrm{aq})+14 \mathrm{H}^{+}(\mathrm{aq}) \rightarrow 6 \mathrm{Fe}^{3+}(\mathrm{aq})+2 \mathrm{Cr}^{3+}(\mathrm{aq})+7 \mathrm{H}_{2} \mathrm{O}(\mathrm{l})
$$

$6.5<\mathrm{pH}<7.5$ :

$$
\begin{gathered}
\mathrm{Cr}_{2} \mathrm{O}_{7}{ }^{2-}(\mathrm{aq})+\mathrm{H}_{2} \mathrm{O}(\mathrm{l}) \rightleftarrows 2 \mathrm{CrO}_{4}{ }^{2-}(\mathrm{aq})+2 \mathrm{H}^{+}(\mathrm{aq}) \\
3 \mathrm{Fe}^{2+}(\mathrm{aq})+\mathrm{CrO}_{4}{ }^{2-}(\mathrm{aq})+4 \mathrm{H}_{2} \mathrm{O}(\mathrm{l}) \rightarrow 3 \mathrm{Fe}^{3+}(\mathrm{aq})+2 \mathrm{Cr}^{3+}(\mathrm{aq})+8 \mathrm{OH}^{-}(\mathrm{aq})
\end{gathered}
$$

$\mathrm{pH}>7.5$ :

$$
\begin{gathered}
\mathrm{Fe}^{2+}(\mathrm{aq})+2 \mathrm{OH}^{-}(\mathrm{aq}) \rightarrow \mathrm{Fe}(\mathrm{OH})_{2}(\mathrm{~s}) \\
3 \mathrm{Fe}(\mathrm{OH})_{2}(\mathrm{~s})+\mathrm{CrO}_{4}{ }^{2-}(\mathrm{aq})+4 \mathrm{H}_{2} \mathrm{O}(\mathrm{l}) \rightarrow 3 \mathrm{Fe}(\mathrm{OH})_{3}(\mathrm{~s})+\mathrm{Cr}(\mathrm{OH})_{3}(\mathrm{~s})+2 \mathrm{OH}^{-}(\mathrm{aq})
\end{gathered}
$$

The extra electrons emitted were also reducing agents and could also reduce chromium (VI) to chromium (III).

$$
\mathrm{Cr}_{2} \mathrm{O}_{7}^{2-}(\mathrm{aq})+14 \mathrm{H}^{+}(\mathrm{aq})+6 \mathrm{e}^{-} \rightarrow 2 \mathrm{Cr}^{3+}(\mathrm{aq})+7 \mathrm{H}_{2} \mathrm{O}(\mathrm{l})
$$

\subsubsection{Effect of Dosage of $\mathrm{H}_{2} \mathrm{SO}_{4}$}

The effect of dosage of $\mathrm{H}_{2} \mathrm{SO}_{4}$ on the reduction efficiency was investigated, while other conditions remained constant-initial concentration of $\mathrm{Cr}(\mathrm{VI})$ of $1.000 \mathrm{~g} / \mathrm{L}$, current density of $0.05 \mathrm{~A}$, and reaction 
temperature of $30^{\circ} \mathrm{C}$. The dosage of $\mathrm{H}_{2} \mathrm{SO}_{4}$ was quantified as the volume, set as $0.00 \mathrm{~mL}, 0.25 \mathrm{~mL}$, $0.50 \mathrm{~mL}, 0.75 \mathrm{~mL}$, and $1.00 \mathrm{~mL}$. The results were shown in Figure 2.

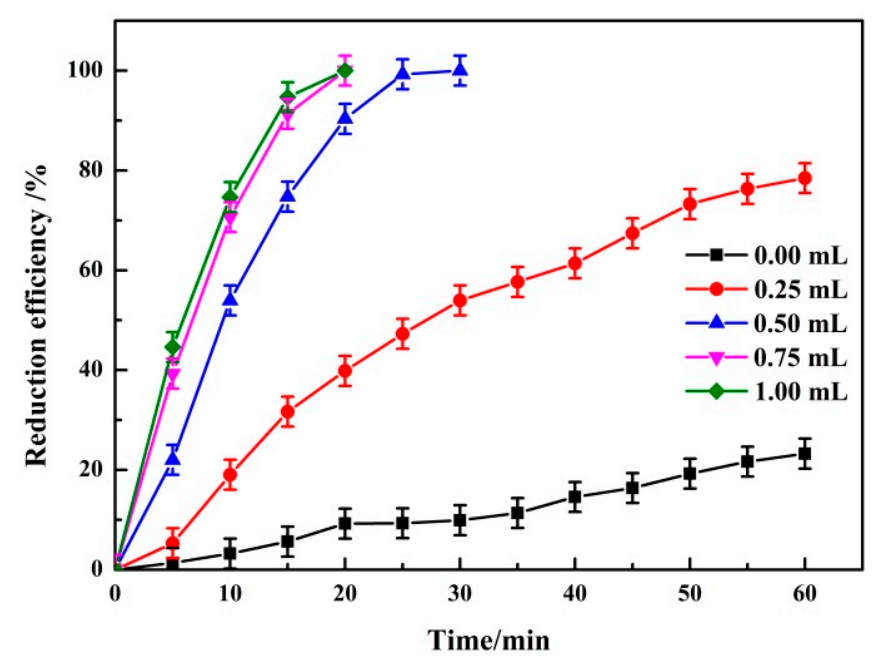

Figure 2. Effect of volume of $\mathrm{H}_{2} \mathrm{SO}_{4}$ on reduction efficiency of chromium. (Initial concentration of $\mathrm{Cr}$ $(\mathrm{VI})=1.000 \mathrm{~g} / \mathrm{L}$, current intensity $=0.05 \mathrm{~A})$.

The results indicated that the reduction efficiency of chromium increased with the increasing of reaction time and acid concentration. The reduction of chromium (VI) in the process was acid-dependent, and higher chromium (VI) reduction efficiency could be achieved at high acid concentration. The acceleration of $\mathrm{Cr}(\mathrm{VI})$ reduction in the system at the high acid concentration could be attributed to the following factors: (I) Chromium (VI) species were more easily reduced in acidic conditions than in neutral or alkaline conditions, according to Equations (17) and (18). The molar fraction of the $\mathrm{Cr}_{2} \mathrm{O}_{7}{ }^{2-}$ was drastically increased with increasing acid concentration.

$$
\begin{array}{cc}
\mathrm{Cr}_{2} \mathrm{O}_{7}{ }^{2-}+14 \mathrm{H}^{+}+6 \mathrm{e}^{-} \rightarrow 2 \mathrm{Cr}^{3+}+7 \mathrm{H}_{2} \mathrm{O} & \mathrm{E}^{0}=1.36 \mathrm{~V} \\
\mathrm{CrO}_{4}{ }^{2-}+4 \mathrm{H}_{2} \mathrm{O}+3 \mathrm{e}^{-} \rightarrow \mathrm{Cr}(\mathrm{OH})_{4}{ }^{-}+4 \mathrm{OH}^{-} & \mathrm{E}^{0}=-1.30 \mathrm{~V}
\end{array}
$$

(II) The corrosion of steel slice was accelerated at high acid concentration, which made the $\mathrm{Fe}^{2+}$ more exposed and reacted with chromium (VI) like Equation (11). (III) the acidic conditions also promoted the conductivity of the solution, which then increased the reduction of chromium because of the increasing amount of extra free-electron (Equation (16)).

\subsubsection{Effect of Reaction Temperature}

During the process, reaction temperature is an important parameter affecting the reaction during the diffusion process [13]. The effect of reaction temperature on the reduction efficiency was tested, while other conditions kept constant-initial concentration of chromium (VI) of $1.000 \mathrm{~g} / \mathrm{L}$, current density of $0.05 \mathrm{~A}$, and dosage of $\mathrm{H}_{2} \mathrm{SO}_{4}$ of $0.50 \mathrm{~mL}$. The results showed in Figure 3 indicated that the reduction of chromium (VI) could be easily achieved at higher reaction temperature. High temperature would decrease the diffusion resistance and favor the contact of $\mathrm{Fe}^{2+}$ and chromium (VI), resulting in high reduction efficiency. 


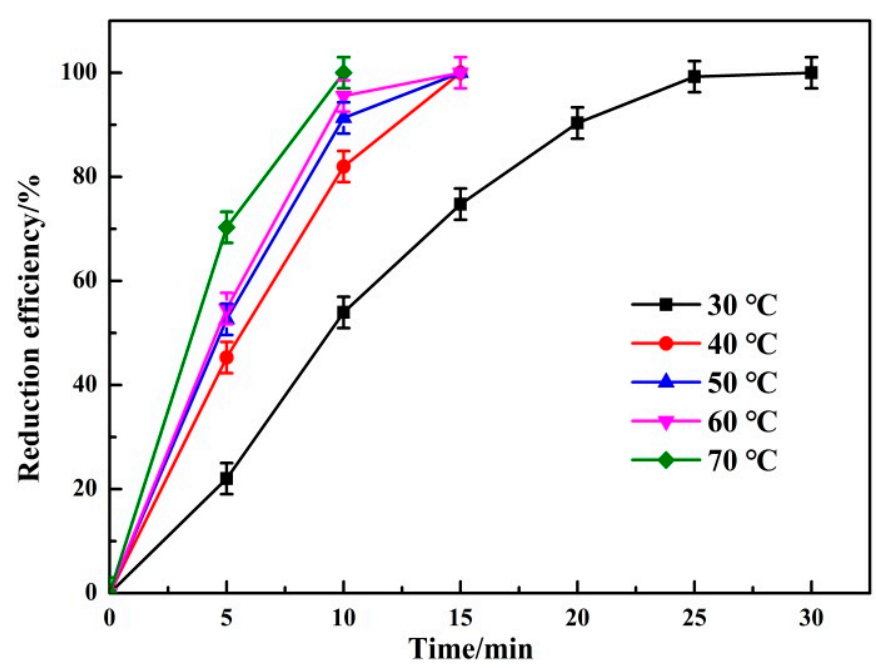

Figure 3. Effect of reaction temperature on reduction efficiency of chromium. (Volume of $\mathrm{H}_{2} \mathrm{SO}_{4}=0.50 \mathrm{~mL}$, initial concentration of $\mathrm{Cr}(\mathrm{VI})=1.000 \mathrm{~g} / \mathrm{L}$, Current intensity $\left.=0.05 \mathrm{~A}\right)$.

\subsubsection{Effect of Current Intensity}

The results showed in Figure 4 summarized the effect of current intensity on the reduction efficiency. It could be concluded that the current intensity had no obvious effect on the reduction efficiency, as the reduction efficiency increased little as current increased from $0.01 \mathrm{~A}$ to $0.05 \mathrm{~A}$.

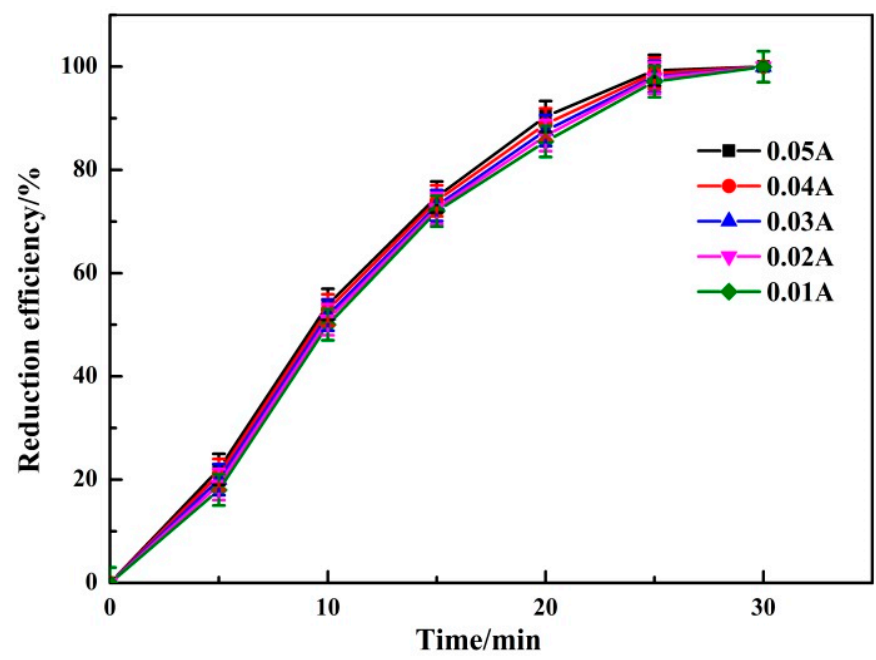

Figure 4. Effect of current intensity on reduction efficiency of chromium. (Volume of $\mathrm{H}_{2} \mathrm{SO}_{4}=0.50 \mathrm{~mL}$, initial concentration of $\mathrm{Cr}(\mathrm{VI})=1.000 \mathrm{~g} / \mathrm{L})$.

\subsection{Response Surface Methodology}

\subsubsection{Experimental Design}

The single factor experiment was time intensive and ignored the effects of the interactions between different factors. Response surface methodology was used to observe both the effect of the independent variables on the response as well as their possible interactions [29-31]. In this study, the Design-Expert software was used to design the experiments. Central composite design (CCD) was applied to investigate the effects of parameters on the reduction efficiency of chromium. The operation parameters included: A: dosage of $\mathrm{H}_{2} \mathrm{SO}_{4}$, B: current intensity, C: reaction time, and D: reaction temperature. The actual values for each parameter are detailed in Table 1. 
Table 1. Levels for parameters in actual values.

\begin{tabular}{lcccc}
\hline & \multirow{2}{*}{ Independent Parameter } & Unit & \multicolumn{4}{c}{ Level } \\
\cline { 3 - 5 } & & $\mathbf{- 1}$ & $\mathbf{0}$ & $\mathbf{1}$ \\
\hline $\mathrm{A}: \mathrm{H}_{2} \mathrm{SO}_{4}$ & $\mathrm{~mL}$ & 0 & 0.5 & 1.0 \\
B: Current Intensity & $\mathrm{A}$ & 0.01 & 0.03 & 0.05 \\
$\mathrm{C}:$ Reaction Time & $\mathrm{min}$ & 5 & 17.5 & 30 \\
D: Reaction Temperature & ${ }^{\circ} \mathrm{C}$ & 30 & 45 & 60 \\
\hline
\end{tabular}

\subsubsection{Model Fitting}

The natural logarithm, which was presented in terms of the coded values for the reduction efficiency after insignificant terms were excluded, and shown in Equation (19):

$$
\begin{aligned}
& \operatorname{Ln}(\eta)=-5.05833+8.80332 \times A+31.11897 \times B+0.18792 \times C+0.15777 \times D+0.27417 \times A \times B \\
& -2.21816 E-003 \times A \times C-1.32521 E-003 \times A \times D+0.054482 \times B \times C-0.14186 \times B \times D- \\
& 1.06258 E-003 \times C \times D-5.86586 \times A^{2}-399316804 \times B^{2}-2.37553 E \times C^{2}-1.17429 E-003 \times D^{2}
\end{aligned}
$$

The results of the responses for reduction efficiency in the form of analysis of variance were indicated in Table 2. The $F$-value and $p$-value for the mode1 was 61.87 and $<0.0001$, respectively, which indicated the model was significant and could be used to monitor the optimization. The $p$-value of $\mathrm{A}$, $C$, and D were all $<0.0001$, which indicated that $A, C$, and D affected the results significantly, which was consistent with the results above.

Table 2. Analysis of variance for the response.

\begin{tabular}{cccccc}
\hline Source & Sum of Squares & $\mathbf{Z}$ & Mean Square & F Value & $\boldsymbol{p}$-Value Prob $>$ F \\
\hline Model & 79.95 & 14 & 5.71 & 61.87 & $<0.0001$ \\
A & 36.48 & 1 & 36.48 & 395.23 & $<0.0001$ \\
B & 0.025 & 1 & 0.025 & 0.27 & 0.6080 \\
C & 9.40 & 1 & 9.40 & 101.82 & $<0.0001$ \\
D & 3.31 & 1 & 3.31 & 35.83 & $<0.0001$ \\
Residual & 1.38 & 15 & 0.092 & - & - \\
Lack-of-fit & 1.38 & 10 & 0.14 & - & - \\
Pure error & 0.000 & 5 & 0.000 & - & - \\
\hline \multicolumn{5}{c}{}
\end{tabular}

\subsubsection{Response Surface Analysis}

The residuals were almost located at a straight line, as shown in Figure 5, which indicated that the errors exhibited a normal distribution. The plot of the predicted versus the actual responses was summarized in Figure 6. The results showed that the predicted values were in good agreement with the experimental values, indicating that the model was valid and successfully fits the experimental data. Furthermore, Figure 7 showed that the residuals scattered randomly, which implied that the models suggested were adequate and there was no reason to suspect any violation of the independence or constant variance assumption. 


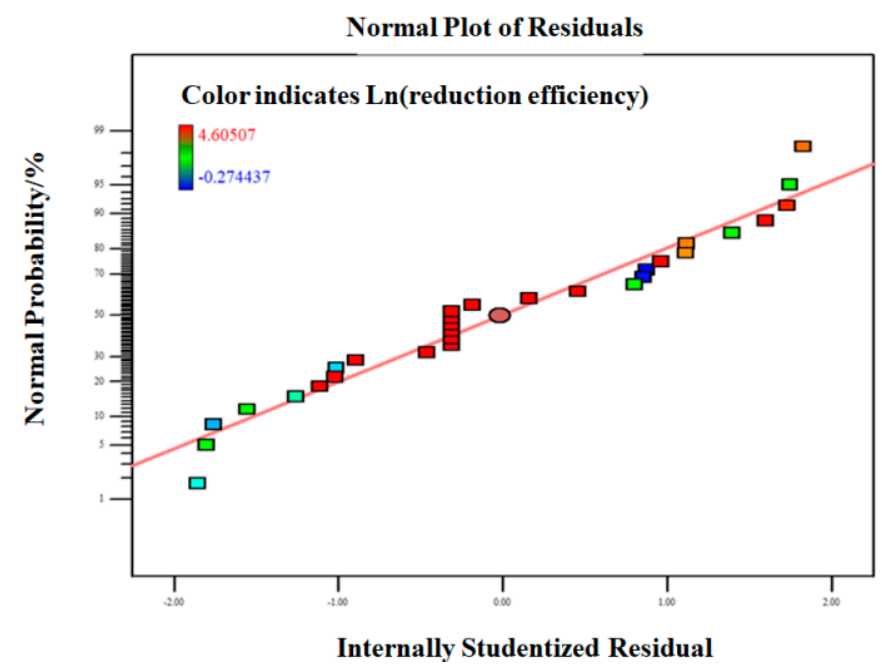

Figure 5. Normal probabilities of the residuals.

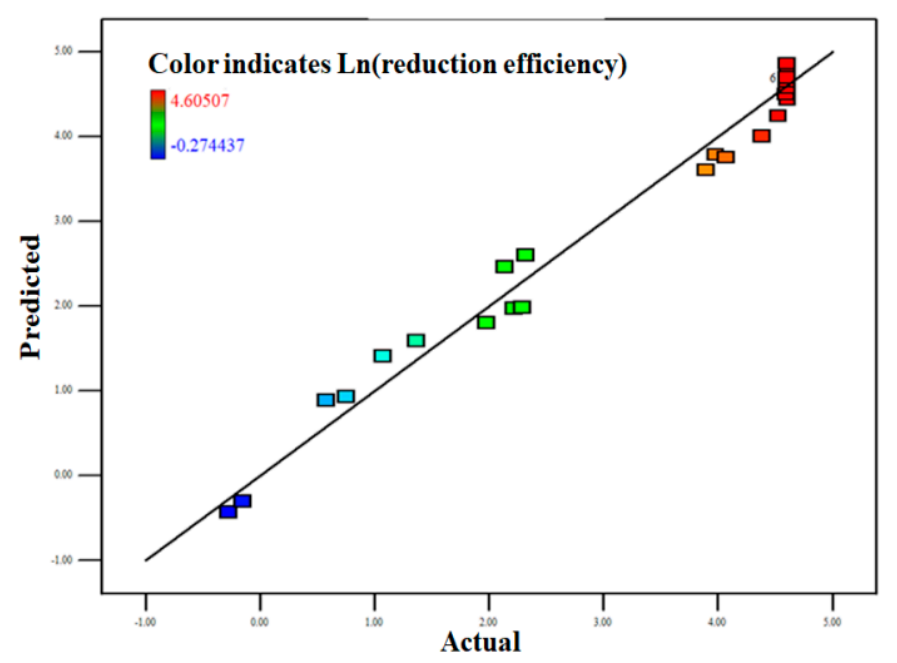

Figure 6. Plot of the predicted responses vs. the actual values.

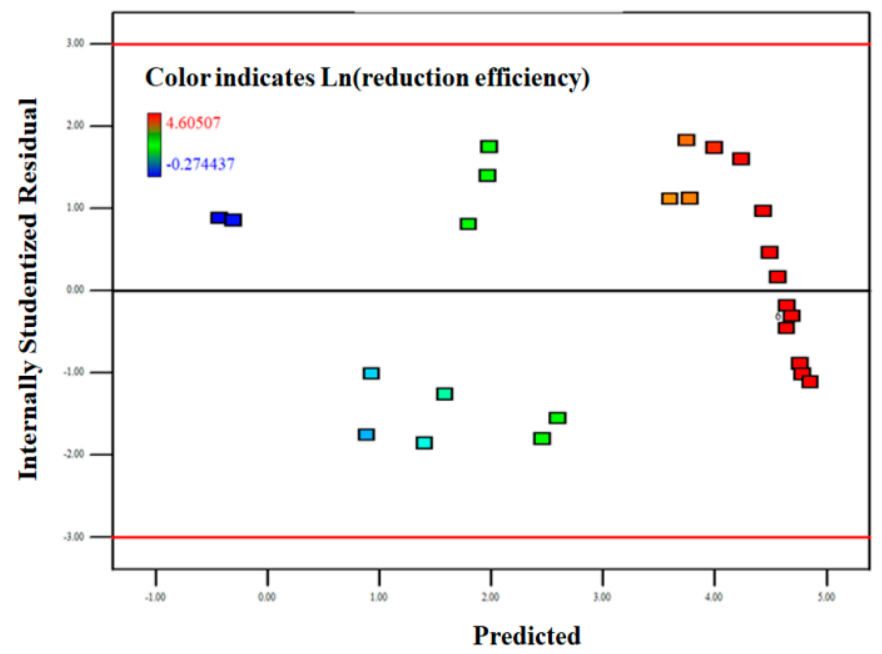

Figure 7. Plot of the residual responses vs. the predicted responses.

A perturbation plot (Figure 8) showed a comparison of all the parameters at a selected point in a chosen design space. The reduction efficiency was modeled by changing only one parameter at its range, while others held constant. The simulation results indicated that the influence of the single 
parameter on the reduction efficiency followed the order: A: dosage of $\mathrm{H}_{2} \mathrm{SO}_{4}>\mathrm{C}$ : reaction time > D: reaction temperature $>\mathrm{B}$ : current intensity. The comparatively sharp line of the dosage of $\mathrm{H}_{2} \mathrm{SO}_{4}$ significantly affected the reduction efficiency in the design space. That is, the coefficient of the dosage of $\mathrm{H}_{2} \mathrm{SO}_{4}$ in Equation (19) was extremely high. Equation (19) and the perturbation plot showed that the current intensity exhibited curvature effects. The reduction efficiency approximately increased linearly with increasing reaction time and reaction temperature in the chosen design space.

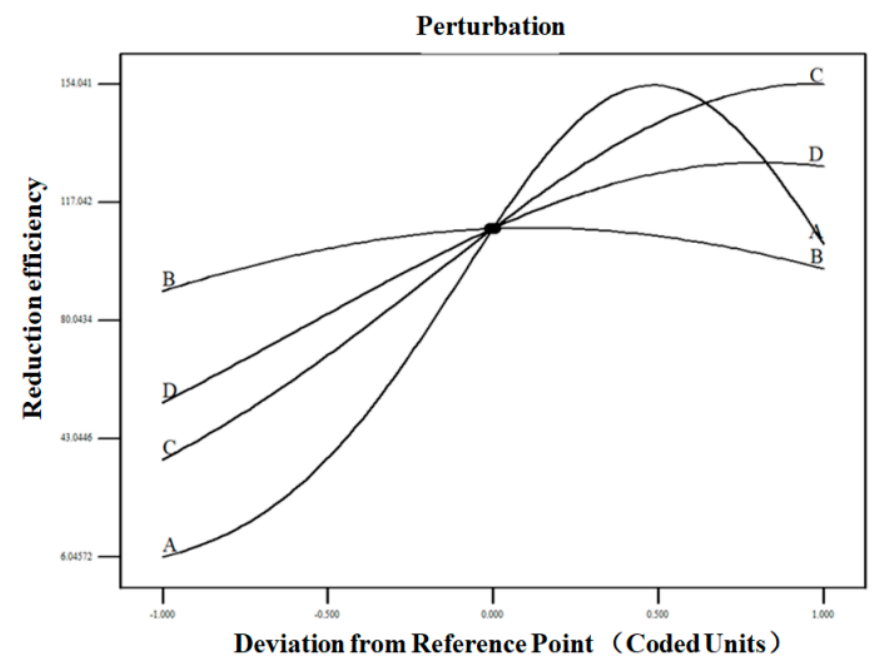

Figure 8. Perturbation plot for the reduction efficiency of vanadium in the design space: A: dosage of $\mathrm{H}_{2} \mathrm{SO}_{4}$, B: current intensity, $\mathrm{C}$ : reaction time, D: reaction temperature.

The 3D Response surfaces were plotted to understand both the main and interactive effects between two affected parameters. Figure 9 summarized the interaction of each affected parameter. The results showed that the reduction efficiency of chromium first increased with the increase of dosage of $\mathrm{H}_{2} \mathrm{SO}_{4}$, while other parameters held constant and then decreased as the volume of $\mathrm{H}_{2} \mathrm{SO}_{4}$ $>0.8 \mathrm{~mL}$. Also, reaction time and reaction temperature were important parameters affecting the reduction efficiency, which was consistent with the common results. The current intensity had no obvious influence on the reduction efficiency; it was only needed to apply an appropriate potential or current intensity during the process.
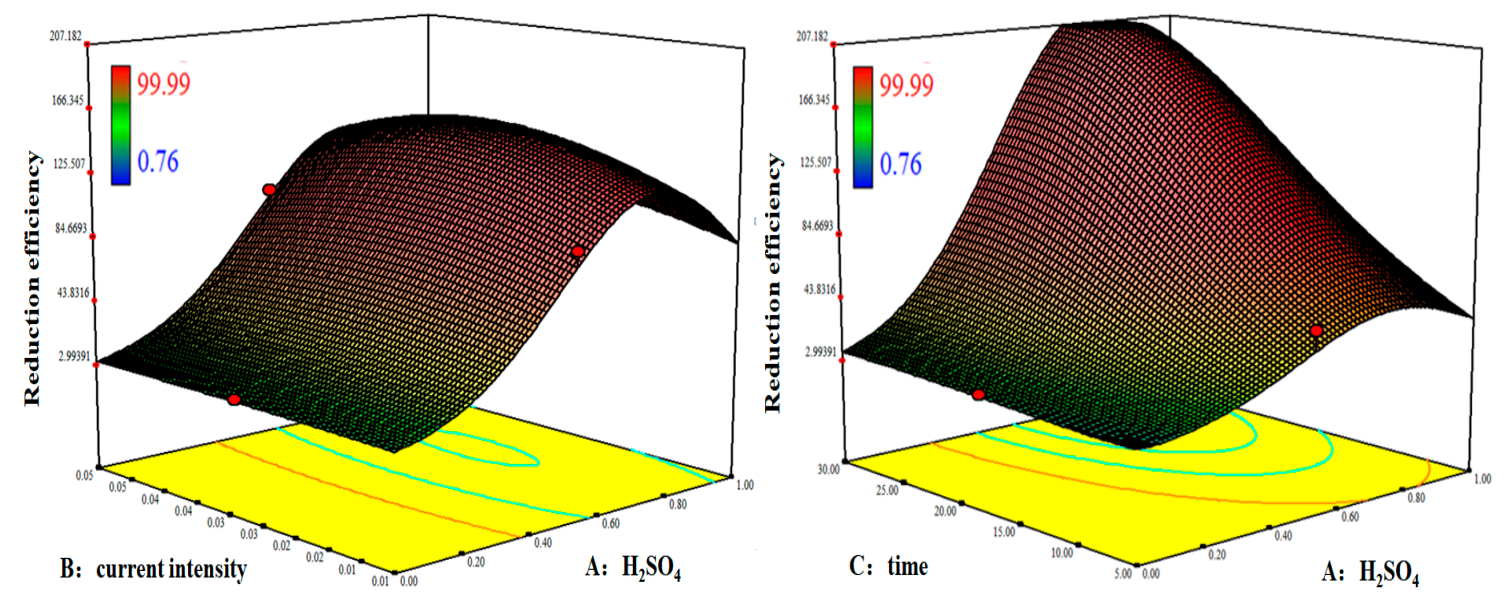

Figure 9. Cont. 

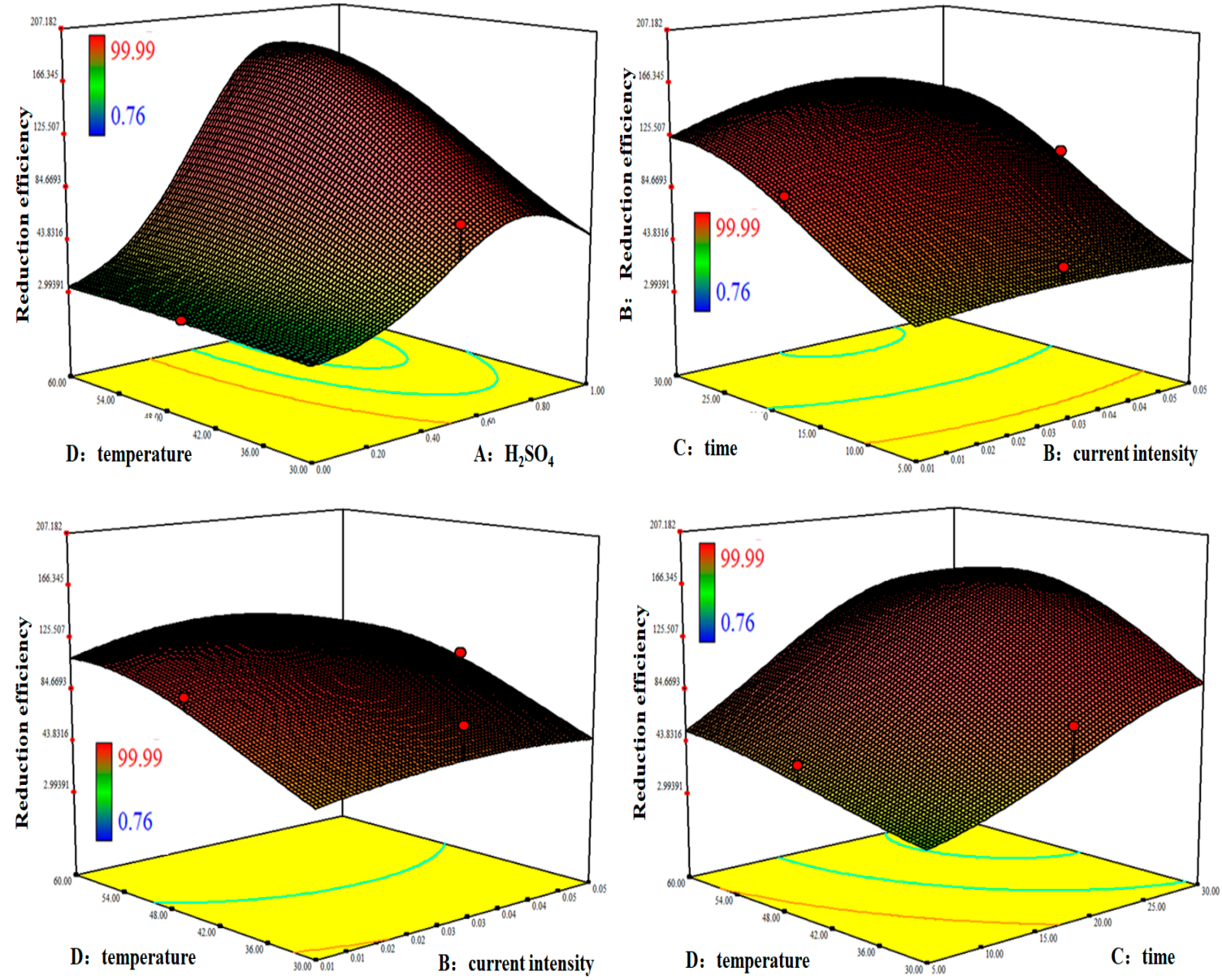

Figure 9. 3D Response surfaces of reduction efficiency.

In summary, the reduction efficiency of chromium was affected significantly by dosage of $\mathrm{H}_{2} \mathrm{SO}_{4}$ and reaction temperature, and reaction time came second, while current intensity was the last.

\subsection{Removal of Chromium (III)}

After reduction process, the chromium in the solution was existed as $\mathrm{Cr}$ (III) and it was removed by hydrolysis precipitation method [32]. Chromic hydroxide was precipitated with the addition of $\mathrm{NaOH}$ and filtration.

\section{Conclusions}

In this study, an electrocoagulation-like technology electro-reduction was applied to reduce hexavalent chromium to trivalent chromium. The main results were summarized as follows:

(1) The reduction efficiency was affected significantly by dosage of $\mathrm{H}_{2} \mathrm{SO}_{4}$. The results optimized by response surface methodology indicated that the influence of single factor on the reduction efficiency followed the order: A: dosage of $\mathrm{H}_{2} \mathrm{SO}_{4}>\mathrm{C}$ : reaction time $>$ D: reaction temperature $>$ B: current intensity.

(2) The reduction efficiency was hardly affected by current intensity, while it was increased with the increasing of reaction time and acid concentration. The reducing agent, $\mathrm{Fe}^{2+}$ and an extra free electron, acted as the reducing agent and could easily reduce hexavalent chromium to trivalent chromium at high temperature in acid medium. 
Author Contributions: Conceptualization, H.P.; formal analysis, Q.C. and Q.S.; funding acquisition, H.P.; investigation, Q.C. and Y.L.; methodology, H.P.; project administration, H.P.; software, J.G.; supervision, H.P.; validation, H.P. and J.S.; writing—original draft, H.P.; writing—review and editing, H.P.

Funding: This work was supported by the Science and Technology Project of Chongqing, China (No. cstc2018jcyjAX0018), National Natural Science Foundation of China (No.21576033), and Talent Introduction Project of Yangtze Normal University (No.2017KYQD117).

Conflicts of Interest: The authors declare no conflict of interest.

\section{References}

1. Lu, D.; Yang, M.; Fang, P.; Li, C.; Jiang, L. Enhanced photocatalytic degradation of aqueous phenol and Cr (VI) over visible-light-driven $\mathrm{Tb}_{\mathrm{x}} \mathrm{O}_{\mathrm{y}}$ loaded $\mathrm{TiO}_{2}$-oriented nanosheets. Appl. Surf. Sci. 2017, 399, 167-184. [CrossRef]

2. Zadorozhnyy, V.Y.; Klyamkin, S.N.; Zadorozhnyy, M.Y.; Bermesheva, O.V.; Kaloshkin, S.D. Mechanical alloying of nanocrystalline intermetallic compound TiFe doped by aluminum and chromium. J. Alloys Compd. 2014, 586, S56-S60. [CrossRef]

3. Ma, H.; Zhou, J.; Hua, L.; Cheng, F.; Zhou, L.; Qiao, X. Chromium recovery from tannery sludge by bioleaching and its reuse in tanning process. J Clean Prod. 2017, 142, 2752-2760. [CrossRef]

4. Zhao, J.; Liu, M.; Liang, M.; Ding, B.; Ding, K.; Pan, Y. Organics Wastewater Degradation by a Mesoporous Chromium-Functionalized $\gamma-\mathrm{Al}_{2} \mathrm{O}_{3}$ with $\mathrm{H}_{2} \mathrm{O}_{2}$ Assistance. Water Air Soil Pollut. 2018, 229, 135. [CrossRef]

5. Xu, X.-R.; Li, H.-B.; Li, X.-Y.; Gu, J.-D. Reduction of hexavalent chromium by ascorbic acid in aqueous solutions. Chemosphere 2004, 57, 609-613. [CrossRef]

6. Nasseh, N.; Taghavi, L.; Barikbin, B.; Khodadadi, M. Advantage of almond green hull over its resultant ash for chromium(VI) removal from aqueous solutions. Int. J. Environ. Sci. Technol. 2017, 14, 251-262. [CrossRef]

7. Jyothi, M.S.; Nayak, V.; Padaki, M.; Balakrishna, R.G.; Soontarapa, K. Eco-friendly membrane process and product development for complete elimination of chromium toxicity in wastewater. J. Hazard. Mater. 2017, 332, 112-123. [CrossRef]

8. He, X.; Qiu, X.; Chen, J. Preparation of Fe(II)-Al layered double hydroxides: Application to the adsorption/reduction of chromium. Colloids Surf. A Physicochem. Eng. Aspects 2017, 516, 362-374. [CrossRef]

9. Li, S.; Liu, L.; Yu, Y.; Wang, G.; Zhang, H.; Chen, A. $\mathrm{Fe}_{3} \mathrm{O}_{4}$ modified mesoporous carbon nanospheres: Magnetically separable adsorbent for hexavalent chromium. J. Alloys Compd. 2017, 698, 20-26. [CrossRef]

10. Fu, R.; Zhang, X.; Xu, Z.; Guo, X.; Bi, D.; Zhang, W. Fast and highly efficient removal of chromium (VI) using humus-supported nanoscale zero-valent iron: Influencing factors, kinetics and mechanism. Sep. Purif. Technol. 2017, 174, 362-371. [CrossRef]

11. Ouyan, X.; Han, Y.; Cao, X.; Chen, J. Magnetic biochar combining adsorption and separation recycle for removal of chromium in aqueous solution. Water Sci. Technol. 2017, 75, 1177-1184.

12. Hua, M.; Yang, B.; Shan, C.; Zhang, W.; He, S.; Lv, L.; Pan, B. Simultaneous removal of As(V) and Cr(VI) from water by macroporous anion exchanger supported nanoscale hydrous ferric oxide composite. Chemosphere 2017, 171, 126-133. [CrossRef] [PubMed]

13. Peng, H.; Guo, J.; Li, B.; Liu, Z.; Tao, C. High-efficient recovery of chromium (VI) with lead sulfate. J. Taiwan Inst. Chem. Eng. 2018, 85, 149-154. [CrossRef]

14. Lu, J.; Wang, Z.; Liu, Y.; Tang, Q. Removal of Cr ions from aqueous solution using batch electrocoagulation: Cr removal mechanism and utilization rate of in situ generated metal ions. Process Saf. Environ. Prot. 2016. [CrossRef]

15. Zhu, Y.; Li, H.; Zhang, G.; Meng, F.; Li, L.; Wu, S. Removal of hexavalent chromium from aqueous solution by different surface-modified biochars: Acid washing, nanoscale zero-valent iron and ferric iron loading. Bioresour. Technol. 2018, 261, 142-150. [CrossRef] [PubMed]

16. Yin, W.; Li, Y.; Wu, J.; Chen, G.; Jiang, G.; Li, P.; Gu, J.; Liang, H.; Liu, C. Enhanced Cr(VI) removal from groundwater by Fe 0 -H 2 O system with bio-amended iron corrosion. J. Hazard. Mater. 2017, 332, 42-50. [CrossRef] [PubMed]

17. Nhat-Thien, N.; Lee, S.-Y.; Chen, S.-S.; Nguyen-Cong, N.; Chang, C.-T.; Hsiao, S.-S.; le Thuy, T.; Kao, C.-Y.; Lin, M.-F.; Wang, L. Preparation of Zn-Doped Biochar from Sewage Sludge for Chromium Ion Removal. J. Nanosci. Nanotechnol. 2018, 18, 5520-5527. [CrossRef] 
18. Wei, Y.; Fang, Z.; Zheng, L.; Tsang, E.P. Biosynthesized iron nanoparticles in aqueous extracts of Eichhornia crassipes and its mechanism in the hexavalent chromium removal. Appl. Surf. Sci. 2017, 399, 322-329. [CrossRef]

19. Liu, T.; Zhao, L.; Sun, D.; Tan, X. Entrapment of nanoscale zerovalent iron in chitosan beads for hexavalent chromium removal from wastewater. J. Hazard. Mater. 2010, 184, 727-730. [CrossRef]

20. Wang, Z.; Zheng, S.; Wang, S.; Qin, Y.; Du, H.; Zhang, Y. Electrochemical decomposition of vanadium slag in concentrated $\mathrm{NaOH}$ solution. Hydrometallurgy 2015, 151, 51-55. [CrossRef]

21. Peng, H.; Liu, Z.; Tao, C. Selective leaching of vanadium from chromium residue intensified by electric field. J. Environ. Chem. Eng. 2015, 3, 1252-1257. [CrossRef]

22. Peng, H.; Liu, Z.; Tao, C. Leaching Kinetics of Vanadium with Electro-oxidation and $\mathrm{H}_{2} \mathrm{O}_{2}$ in Alkaline Medium. Energy Fuels 2016, 30, 7802-7807. [CrossRef]

23. Vasudevan, S.; Lakshmi, J.; Sozhan, G. Studies on the Removal of Iron from Drinking Water by Electrocoagulation-A Clean Process. CLEAN-Soil Air Water 2009, 37, 45-51. [CrossRef]

24. Bazrafshan, E.; Moein, H.; Mostafapour, F.K.; Nakhaie, S. Application of Electrocoagulation Process for Dairy Wastewater Treatment. J. Chem. 2013, 2013, 640139. [CrossRef]

25. Sahu, O.; Mazumdar, B.; Chaudhari, P.K. Treatment of wastewater by electrocoagulation: A review. Environ. Sci. Pollut. Res. 2014, 21, 2397-2413. [CrossRef] [PubMed]

26. Yang, H.; Xu, X.; Neumann, I. Optimal finite element model with response surface methodology for concrete structures based on Terrestrial Laser Scanning technology. Compos. Struct. 2018, 183, 2-6. [CrossRef]

27. Souza, L.P.; Faroni, L.R.D.; Heleno, F.F.; Pinto, F.G.; Queiroz, M.; Prates, L.H.F. Ozone treatment for pesticide removal from carrots: Optimization by response surface methodology. Food Chem. 2018, 243, 435-441. [CrossRef]

28. Zarei, S.; Niad, M. Cystoseira myricaas for mercury (II) uptake: Isotherm, kinetics, thermodynamic, response surface methodology and fuzzy modeling. J. Taiwan Inst. Chem. Eng. 2017, 81, 247-257. [CrossRef]

29. Yuan, Y.; Tan, L.; Xu, Y.; Dong, J.; Zhao, Y.; Yuan, Y. Optimization of Processing Parameters for Lettuce Vacuum Osmotic Dehydration Using Response Surface Methodology. Pol. J. Food Nutr. Sci. 2018, 68. [CrossRef]

30. Nawaz, H.; Shad, M.A.; Rauf, A. Optimization of extraction yield and antioxidant properties of Brassica oleracea Convar Capitata Var L. leaf extracts. Food Chem. 2018, 242, 182-187. [CrossRef]

31. Rosid, S.J.M.; Bakar, W.A.W.A.; Ali, R. Characterization and modelling optimization on methanation activity using Box-Behnken design through cerium doped catalysts. J. Clean. Prod. 2018, 170, 278-287. [CrossRef]

32. Chen, B.; Huang, S.; Liu, B.; Ge, Q.; Wang, M.; Wang, X. Separation and recovery of vanadium and chromium from acidic leach solution of V-Cr-bearing reducing slag. J. Environ. Chem. Eng. 2017, 5, 4702-4706. [CrossRef] 